NBER WORKING PAPER SERIES

\title{
ARE FOR-PROFIT HOSPITALS REALLY DIFFERENT? MEDICARE UPCODING AND MARKET STRUCTURE
}

\author{
Elaine Silverman \\ Jonathan Skinner \\ Working Paper 8133 \\ http://www.nber.org/papers/w8133 \\ NATIONAL BUREAU OF ECONOMIC RESEARCH \\ 1050 Massachusetts Avenue \\ Cambridge, MA 02138 \\ February 2001
}

We thank David Cutler, Elliott Fisher, Jill Horwitz, Louise Sheiner, and conference participants at the NBER Conference on Not-for-Profit Health Care, Nashville TN (April 2000) for very helpful comments and suggestions. We are indebted to Thomas Bubolz and Sandra Sharp for invaluable assistance in creating the Medicare data set. Finally, we acknowledge gratefully financial assistance from the National Institute on Aging, NBER, and the Robert Wood Johnson Foundation. The views expressed herein are those of the authors and not necessarily those of the National Bureau of Economic Research.

(C) 2001 by Elaine Silverman and Jonathan Skinner. All rights reserved. Short sections of text, not to exceed two paragraphs, may be quoted without explicit permission provided that full credit, including (C) notice, is given to the source. 
Are For-Profit Hospitals Really Different? Medicare Upcoding and Market Structure Elaine Silverman and Jonathan Skinner

NBER Working Paper No. 8133

February 2001

JEL No. L3, I1

\begin{abstract}
$\underline{\text { ABSTRACT }}$
How do for-profit and not-for-profit hospitals differ? We consider one dimension: the shifting of a patient's diagnostic related group (DRG) to one that yields a greater reimbursement from the Medicare system, also known as upcoding. It has played a major role in recent federal lawsuits against hospitals and hospital chains, but more importantly provides a valuable window for understanding how for-profit and not-for-profit hospitals make tradeoffs between pecuniary benefits and reputational or penalty costs. Our empirical work focuses primarily on hospital admissions involving pneumonia and respiratory infections; while the two diagnostic categories are often difficult to distinguish from one another, the latter pays about $\$ 2000$ more to the hospital. Between 1989 and 1996, the incidence of the most expensive DRG (relative to all DRGs for pneumonia and respiratory infections) rose by 10 percentage points among stable not-for-profit hospitals, 23 percent among stable for-profit hospitals, and 37 percentage points among hospitals that had converted to for-profit status. (Since 1996, the upcoding index has dropped significantly in response to adverse publicity and lawsuits.) There is some evidence that not-for-profit hospitals operating in heavily for-profit markets were almost as likely to upcode as their for-profit brethren, as well as for important regional effects.
\end{abstract}

Elaine Silverman

Department of General Internal Medicine

Dartmouth-Hitchcock Medical Center Lebanon NH 03756

elaine.silverman@dartmouth.edu
Jonathan Skinner

Department of Economics

Dartmouth College

Hanover NH 03755

and NBER

jonathan.skinner@dartmouth.edu 


\section{Introduction}

There are at least two long-standing debates regarding for-profit and not-for-profit hospitals. The first is whether for-profit hospitals are different from not-for-profit hospitals in any substantive way beyond the fact that for-profits pay taxes on their profits. Here the gamut of opinion ranges widely, from the view that for-profit and not-for-profit hospitals are similar, to the view that for-profits charge more and provide lower quality care. ${ }^{1}$ The second debate is how for-profit and not-for-profit hospitals interact in a given market. Again, views range widely. In one view, not-for-profit hospitals may set standards of conduct that influence for-profit hospitals operating in the same market (Hansmann, 1980). ${ }^{2}$ Another view suggests that the reverse effect may hold; not-for-profit hospitals end up copying more aggressive for-profit business practices, as in Cutler and Horwitz (1999). ${ }^{3}$ Finally, Lakdwawalla and Philipson (1999) argue that not-forprofit behavior (in their case, nursing homes) should exert no influence on the behavior of forprofits, since for-profits, with their higher operating costs and lack of charitable endowments, are by definition the marginal firm and hence determine market price and quality combinations.

In this paper, we focus on the propensity of different hospitals to engage in upcoding, or shifting a patient's diagnostic related group (or DRG) to one that yields a greater reimbursement from the Medicare system. As we discuss below, there are just a few categories of diseases

\footnotetext{
${ }^{1}$ For an excellent review, see Sloan (2000); also see Patel et al (1994), Sloan et al (1998), Taylor, Whellan, and Sloan (1999), Woolhandler and Himmelstein (1999), and others.

2 For example, Hansmann (1980) writes "Also, in industries such as nursing homes, the presence of a substantial number of for-profit competitors may weaken normative restraints; the standards of service and conduct set by the proprietary firms eventually may be taken as an acceptable minimum even among the nonprofits." (p. 78 in the Rose-Ackerman (1986) reprint). The flip side of this is that high concentrations of not-for-profit hospitals should induce stronger "normative restraints" among for-profits.

3 See Langley (1997), who quotes a former senior vice president of Baptist Hospital, a not-for-profit in the (heavily for-profit) Nashville market, on expansion plans: "We're no less inclined or more inclined to be nonprofit or forprofit - just whatever is to our advantage." (p. A6)
} 
where upcoding is feasible, often where there is genuine clinical uncertainty about appropriate diagnosis. Nevertheless, upcoding behavior provides a valuable window into the economic behavior of hospitals, because it reflects both hospital employee behavior towards risk (including risk of criminal prosecution) and returns, as well as providing an implicit valuation of the community "trust signal" (Hansmann, 1980; Frank and Salkever, 1994). Changes in the composition of Medicare billing codes can have implications for other issues as well. At least in the Medicare population, we find that between 1989-1996, upcoding added one percentage point annually to the real quality-adjusted medical care price index for the treatment of pneumonia and related respiratory diseases.

Our analysis is based on a 20 percent sample of Medicare inpatient claims at the hospital level between 1989 and 1997. We use the Dartmouth Atlas's hospital service area (HSA) as our definition of the relevant market (Wennberg and Cooper, 1999). At the hospital level, this means that hospital markets are defined by whether hospitals are located in the same city or town. ${ }^{4}$ For hospital markets, our definition is clearly not perfect, since hospitals in adjacent towns may compete, or cities may encompass large areas (e.g., Los Angeles). Nevertheless, our market definition is not endogenous with respect to the market strategies of individual hospitals.

We consider the DRG coding for pneumonia and the closely related DRG coding for respiratory complications. We focus primarily on respiratory-related diagnoses here for three reasons. Respiratory-related diagnoses have figured prominently in both the recent federal lawsuit against Columbia/HCA, the large for-profit hospital chain, and were the focus of the original investigation by the New York Times (Gottlieb et al, 1997). Second, they are large

\footnotetext{
${ }^{4}$ We have also conducted complementary analysis using zip-code based data that is consistent with the results presented below, although they are not presented here.
} 
quantitatively; upcoding costs from these diagnoses alone may have added more than $\$ 100$ million to overall Medicare expenditures annually, relative to a 1989 benchmark. ${ }^{5}$ And finally, because the upcoding ratio for these diagnoses is so elastic with respect to hospital behavior, it is a remarkably sensitive marker of the hospital's general stance towards revenue enhancement from the Medicare program. To test the generality of our results, we also consider DRG claims for stroke and sepsis; these also exhibited evidence of upcoding during the 1990s (e.g., Brown, 1999).

Between 1989 and 1996, the percentage of relevant admissions that consisted of the most expensive respiratory DRG rose by 10 percentage points among stable not-for-profit hospitals, 23 percent among stable for-profit hospitals, and by 37 percentage points among hospitals that had converted from not-for-profit to for-profit between 1989-93. (Since 1996, the upcoding index has dropped significantly in response to adverse publicity and lawsuits.) Thus we find strong evidence that the organizational form of the hospital mattered with regard to upcoding behavior.

There is no evidence that a larger presence of not-for-profit hospitals exerted a moderating influence on upcoding behavior by for-profits, as in Hansmann (1980). However, there is stronger evidence that not-for-profit hospitals operating in heavily for-profit markets behaved much like their for-profit brethren, showing similar degrees of upcoding. In addition, there are important regional effects with regard to upcoding more generally. All hospitals in the South -- for-profit, not-for-profit, and government -experienced a more rapid growth in upcoding than other parts of the county. Similarly, all hospitals in the Northeast experienced a much lower degree of upcoding. As we discuss below, these empirical results are consistent with models of

\footnotetext{
5 The ratio of DRG 79 to all four DRG categories rose by 12 percentage points between 1989 and 1996, although it has fallen since; see the November 19, 1998 memo by Gregory Savord, Special Assistant to the Chief Actuary,
} 
Young (1986) and Cutler and Seinfeld (2000) in which employees and physicians may sort into different hospitals (or regions) depending on individual preferences for financial reward, philanthropic behavior, and attitudes towards risk.

\section{Theoretical Models}

There are a variety of models developed to explain the economic behavior of not-forprofit hospitals (e.g., Newhouse, 1970; Pauly and Redisch, 1974), as well as to explain the interaction between for-profit and not-for-profit institutions in the same market (Hansmann, 1980; Cutler and Horwitz, 1999; Lakdwawalla and Philipson, 1999). How might upcoding behavior shed light on these models? A first response might be to view upcoding as simply a characteristic of the better ability of for-profits to increase net revenue (e.g., Sear, 1991), and thus divorced from questions regarding the quality of care or the interaction of for-profit and notfor-profit hospitals in the same market. Yet coding decisions are not separate from other types of decisions made by hospitals, either with respect to tradeoffs between quality and net revenue, or with respect to their ability to compete in local markets. First, as we discuss below, physicians play an important role in designating primary diagnostic categories that in turn determine DRG codes submitted to Medicare, so that concerted upcoding behavior must, by necessity, involve the hospital staff. Furthermore, strong upcoding behavior, while providing a pecuniary reward, can also carry serious penalties including the threat of prison sentences. Thus one might suspect that decisions relating to upcoding are likely to be correlated with tradeoffs between cost-cutting and quality of care. ${ }^{6}$

\footnotetext{
HCFA.

${ }^{6}$ Examples of cost cutting include downgrading the quality of surgical gloves, sterilizing and reusing cardiac catheters, and (most commonly) reducing nursing staff sizes; in some cases these methods were vetoed by clinical staff (see Lagnado, 1997).
} 
In considering our model of upcoding, we frame the discussion by focusing on its close parallels with the tax evasion literature (e.g., Allingham and Sandmo, 1972; Yitzhaki, 1974; Skinner and Slemrod, 1985) which in turn is based on the Becker model of crime and punishment (Becker, 1968). In this approach, there is a gain in terms of increased revenue from aggressive upcoding, but there is also the risk of detection and subsequent punishment. As well, there may be a psychic cost to employees of engaging in "gray area" upcoding, similar to a welfare stigma model along the lines of Moffitt (1983).

The basic results from this literature are easily stated in the context of hospital decisions. First, optimizing hospitals will balance the gains from upcoding relative to the penalties from being caught. While for-profit and not-for-profit hospitals will face the same marginal incentives, for-profit hospitals face after-tax dollars, both with respect to gains from upcoding and penalties (but not fines) paid to Medicare. Hence the tax code tends to reduce the variance of an aggressive upcoding strategy for for-profit hospitals.

Second, hospitals will be less likely to upcode the larger are the penalties associated with being investigated. As noted above, the dollar penalties (relative to gains) are not likely to differ between for-profit and not-for-profit hospitals. However, the not-for-profit hospital may fear that Medicare "fraud" investigations will do greater harm to the eleemosynary reputation (or "trust capital," also see Glaeser and Schleifer, 1998) of the hospital in the community, and thus be less likely to engage in upcoding. ${ }^{7}$

On the other hand, we would expect for-profit hospital chains with "brand-name capital" in the sense of Klein and Leffler (1981) to be more circumspect about legal investigations and

\footnotetext{
${ }^{7}$ Logically, citizens might applaud the aggressive efforts of not for profit hospitals to wrest more money from the federal government for the benefit of the community. However, they may also suspect that if the hospital is gaming the federal government, what's to stop them from gaming the local patients or doctors?
} 
"fraud" penalties. In the Klein and Leffler model, firms seek to signal quality by investing in capital that becomes worthless in the event of scandal or public disgrace. That Columbia/HCA changed the name of acquired hospitals to reflect the Columbia/HCA ownership, rather than simply own the hospitals under their original names, would appear to suggest that, in the KleinLeffler framework, Columbia/HCA would have even more incentive than single for-profit hospitals to police their managers to prevent fraud, given the huge cost to all hospitals in the chain even if just a few were caught. ${ }^{8}$ Surprisingly, individual Columbia/HCA hospital managers were said to actually reward hospital managers for upcoding as many DRGs as possible into the more generous "with complications" code compared to the "without complications" code (Lagnado, 1997a). In some respects, they were acting as if they had already lost the brand name capital (see Tirole, 1996).

Risk aversion of the hospital will also affect its propensity to upcode. Suppose for-profit hospitals are risk-neutral profit-maximizers, then they will upcode to the point where the expected marginal gains are equal to expected marginal costs. Now suppose the not-for-profit hospital is operating under the constraint that it shouldn't lose money. Then the penalty function from losing money effectively introduces a concave value function, which would cause the notfor-profit to behave as if it were risk averse, since it seeks to avoid the downside risk of paying a large penalty that sends it into the red.

A somewhat different story would obtain with a bankruptcy provision. If the not-forprofit is struggling to survive, it could become more aggressive in its upcoding behavior so as to maintain solvency. In the unlikely event of detection, it would have to declare bankruptcy. But

\footnotetext{
8 In the month of March 1997, when investigations of Columbia/HCA upcoding (and other activities) became public, the stock value of the corporation dropped by 23 percent. Ultimately, Columbia has been dropped from the corporate name; the chain is now just HCA.
} 
this strategy would dominate the alternative of showing losses (and possibly declaring bankruptcy) with certainty.

To this point, we have characterized for-profits and not-for-profits as institutions. However, it is the managers and staff who ultimately decide and implement upcoding decisions. There are two possible differences between the staff in for-profit and not-for-profit hospitals. First, the incentive structure may differ, depending on the propensity of the hospital board (or central office) to reward or penalize managers for the financial performance of the hospital (e.g., Arnoud, Bertrand, and Hallock, 2000). And second, employees will seek employment with firms that provide the best match in terms of incentives, tradeoffs, and risk characteristics (e.g., Young, 1986; Cutler and Seinfeld, 2000). The medical staff may also sort to different hospitals depending on their philosophical views of for-profit versus not-for-profit incentive structures. There is less theoretical guidance, however, on why upcoding behavior should have differed so strongly across regional areas. Medicare is a federal program with nearly identical payments and penalties across all 50 states. Despite this common structure, managers in different regions responded very differently to the incentives for upcoding.

\section{Clinical Issues}

We focus below on a specific on a specific set of DRGs that relate to three broad clinical conditions: pneumonia; sepsis; and cerebrovascular events (strokes). We choose these DRGs because they are known to be DRGs that have attracted the attention of government investigators as being particularly sensitive to upcoding. ${ }^{9}$ Our primary interest will be the ratio of hospital discharges for DRG 79, respiratory infections and inflammations with complications (with a 
DRG reimbursement weight of 1.65), relative to the sum of discharges for the set of four DRGs that together comprise general respiratory ailments: 79 , as well as 80 (respiratory infections without complications, DRG weight of 0.90), 89 (pneumonia, with complications, DRG weight of 1.09), and 90 (pneumonia, without complications, DRG weight of 0.68). Since Medicare's base payment per unit DRG weight is currently about $\$ 4,000$ (depending on location, teaching hospital status, etc.) there are very large financial benefits of coding for DRG 79 instead of the other three classifications.

Why is pneumonia and related respiratory disease a likely place to find upcoding? It is useful to review briefly the clinical issues in the diagnosis of these diseases. There are two general types of pneumonia, bacterial and viral. ${ }^{10}$ The diagnosis of bacterial pneumonia can be straightforward, relying on classic symptoms (e.g. fever, cough and sputum production) in conjunction with sputum samples and/or the typical X-ray signature of pneumonia in the lungs. If a sputum sample is obtained, the finding of "gram positive" bacteria usually constitutes simple bacterial pneumonia (DRG 89 or 90), because the more common gram-positive organisms are usually responsive to a straightforward regimen of antibiotics. The finding of "gram-negative" bacteria moves the diagnosis into the more complex DRGs 79 and 80, since gram-negative organisms are generally more aggressive and can cause more severe illness. In either case, among elderly Medicare patients, pneumonia is often the final complication that occurs because of poor heart functioning or other problems, and so the mortality rate is quite high; in our sample the one-month mortality rate is 12.8 percent.

\footnotetext{
${ }^{9}$ See Birch, 2000, OIG 1999, www.complianceinfo.com. These DRG codes are therefore by no means randomly chosen. Hospitals now hire outside consultants to monitor their upcoding ratios to forestall government investigation.

${ }^{10}$ A third category, mycoplasma ("atypical") pneumonia, is caused by bacteria, but has a more variable and atypical clinical presentation.
} 
For many patients, however, the diagnosis of pneumonia is more problematic. The sputum sample may be non-diagnostic, or the x-ray findings may not be typical of pneumonia. The pneumonia-like condition may arise out of an exacerbation of heart disease or Chronic Obstructive Pulmonary Disease (COPD), making the diagnosis of simple pneumonia difficult. In addition, the symptoms of viral or mycoplasmal pneumonia may overlap with those of other conditions. In other words, can be subjective whether the disease that landed the patient in the hospital is pneumonia or some pulmonary complication related to pneumonia but arising out of the plethora of other conditions experienced by the patient.

Similarly with stroke and with sepsis, the diagnoses may often be subjective. While a stroke is a neurovascular event that causes impairment of motor or sensory function within the central nervous system, transient ischemic attacks (TIAs) can cause the same symptoms, but by definition the symptoms of a TIA resolve within 24 hours. Stroke symptoms may resolve completely as well, and, since it may be difficult to time the onset of symptoms, the diagnosis may be completely subjective. And, although most strokes are accompanied by objective x-ray findings, many are not (or the x-ray findings are delayed with respect to the clincal presentation). Since the DRG for stroke excluding TIAs (DRG 14) pays substantially more than the DRG that includes TIAs (DRG 15) once again there are strong financial incentives for upcoding from DRG 15 to DRG 14.

Sepsis (DRG 416) is a broad clinical syndrome consisting of multiple systemic effects of severe infection, any number of which might overlap with other simpler infections. The risk of sepsis is usually associated with bacteria in the blood or bacteremia. Often times, however, a patient seems to have sepsis, but bacteria are not isolated from the blood. So for instance, there may be no objective way to tell when a simple urinary tract infection becomes "urosepsis." 
Because there is no obvious pairing of sepsis, we compare discharge rates for sepsis to discharge rates for all causes.

It is difficult to make generalizations about how hospital administrative personnel decide on what to code for Medicare billing. Physicians are usually required to enter either a diagnosis or an ICD-9 code for the disease along with additional complication codes. The billing office is likely to have a set of decision rules to map ICD 9 codes to DRG codes, so the physician is unlikely to actually enter the DRG code. Indirect evidence that hospitals nevertheless provided incentives for upcoding is provided by the sharp drop in complex pneumonia DRGs during 1998, the same year that the government outlawed incentive schemes for higher upcoding rates (Birch, 2000).

There are just a few studies of upcoding in the clinical literature. One older study of upcoding reviewed DRG charges in 1988, and found that DRG coding errors were as likely to be an under-reimbursement as an over-reimbursement (Hsia et al, 1992). There were modest differences between for-profit and private not-for-profit hospitals in the percent of DRG codes entered with error (17.3 percent versus 14.1 percent) and the likelihood of over-reimbursement (57 versus 49 percent). Using more recent data, Psaty et al (1999) found strong evidence of over-reimbursement: just for cardiovascular disease, they suggest that upcoding can account for an annual excess of nearly $\$ 1$ billion in Medicare spending.

\section{Data}

The primary analysis is from the 20 percent MEDPAR file of Medicare claims data for each year 1989 through 1997. We match this sample to the hospital at which the DRG was performed. Our sample therefore includes roughly 5,000 hospitals in each year. The ownership status of the hospital was determined from the American Hospital Association Yearbook in 1989, 
1993, and 1996, and matched to the Medicare claims data by the use of the Medicare provider number.

Our definition of markets is simply the town or city in which the hospital is located, and thus follows the structure of Hospital Service Areas (HSAs) as used in the Dartmouth Atlas of Health Care (Wennberg and Cooper, 1999). There are 3436 HSAs in the United States, with the largest number of HSAs being single hospitals in a town or city, but with the majority of people being located in the larger HSAs with more than one hospital. The primary purpose for defining HSAs in the Dartmouth Atlas is to define zip-code-based regions that correspond to the primary catchment areas for the hospital(s) in the region. Here, we focus on hospital-based data, and thus our definition of "markets" are based simply on the address of the hospital. ${ }^{11}$ One advantage of this approach is that the definition of markets is exogenous to the marketing strategy or quality of the hospital, short of physically moving the hospital to a different location. The disadvantage is that markets will be measured with error, for example in the cases where hospitals in adjacent towns may compete for market share. If anything, then, our definition of market HSAs is too strict, and we may be attributing to "regional" effects competition among hospitals across a wider geographical definition than the town or city.

The market share of for-profit, not-for-profit, and government hospitals are determined by the ratio of total hospital discharges at the outset of the analysis in 1989. We categorize the HSAs into four groups: those with no for-profit market share, those with positive but less than $25 \%$ market share, those with $25 \%-50 \%$ market share, and those with more than $50 \%$ market share.

During this period, there were some changes in ownership categories, and we consider each group in turn. First we compare hospitals with stable ownership (not-for-profit, for-profit, 
and government ownership) during the entire period of analysis $1989-97 .{ }^{12}$ We then consider hospitals (and their markets) in which conversions took place, either from not-for-profit (or government) to for-profit, and from for-profit to either not-for-profit or government.

We also merge the hospital-level data set with cost data from the Medicare Cost Reports for 1993 to test for the impact of financial distress on upcoding behavior. (We viewed 1993 as a good period to measure distress since this was just prior to the large overall runup in upcoding ratios.) For each hospital, we calculated the ratio of total patient revenue to the sum of direct costs plus capital costs attributed to plant and equipment. We created five quintiles in order of most distressed (quintile 1) to least distressed (quintile 5).

\section{Results}

As noted above, we will focus here on the respiratory-related diagnoses in the greatest detail. In Table 1, we want to show first that there have not been any sudden jumps in the prevalence of these diseases in the general population. The first three columns of Table 1 show the ratio of the overall respiratory-related diagnoses (DRGs $79,80,89,90$ ) as a fraction of total hospital discharges in the Medicare (over age 65) population. The ratios are calculated as the ratio of the mean of these specific DRG discharges divided by the mean of total discharges. There is a gradual increase in the ratio across all hospital ownership classes, from 5.1 to 6.2 percent for the not-for-profit (private) hospitals, 6.1 to 7.6 percent among for-profits, and from 7.2 to 8.5 percent for government hospitals. While there are differences in the importance of these admission categories across ownership status, the trends are similar, with a relative overall growth between 1989 and 1997 of 1.1 percentage points among not-for-profit hospitals, 1.4 percent among for-profits, and 1.3 percent in government hospitals.

\footnotetext{
${ }^{11}$ The zip-code-based analysis of upcoding yields similar results to those presented below.

12 Our ownership data comes from the AHA during 1989, 1993, and 1996.
} 
The second set of three columns in Table 1 shows one-month mortality rates. They also how a relatively smooth secular trend that with declines in mortality rates that are similar across ownership status: a drop of 1.3 percentage points in not-for-profits, 1.3 percentage points in forprofits, and 1.6 percentage points in government hospitals. The increase in the percentage of people coded with DRG 79 during the 1990s (and the sudden downturn in 1997) does not appear to be the consequence of sicker patients.

Table 2A (and Figure 1) show the same upcoding ratio where we distinguish among ownership status of hospitals. Among stable not-for-profit hospitals, the upcoding ratio rises from 20 percent in 1989 to 30.1 percent in 1996, with a slight decline to 29.7 percent in 1997. For-profit hospitals experienced more rapid growth in upcoding, from 28.2 percent in 1989 to 51.6 percent in 1996 , followed by a sharp decline to 44.1 percent in 1997 , the year in which widespread criminal upcoding investigations were first made public. Finally, the upcoding behavior of government hospitals is nearly identical to not-for-profit hospitals during this period. $^{13}$

These general trends also suggest a simple exercise that quantifies the importance of upcoding in raising the Medicare-related costs of treatment. Suppose the typical patient admitted under one of these four DRGs in 1989 is similar to the typical patient in 1996. However, because of the higher fraction of patients admitted with higher cost DRGs, overall expenditures have risen by more than 7 percentage points, or an annualized increase of about one percentage point. ${ }^{14}$ In other words, price indexes that do not account for this form of DRG upcoding will

\footnotetext{
${ }^{13}$ We do not present significance tests here, in part because these measures are the ratio of averages instead of averages of ratios; we note however that because of the very large samples involved (more than one million discharges for DRGs 79, 80, 89, and 90) significance is not generally an issue in these calculations.

14 We could calculate the proportional change in Medicare expenditures for each ownership category, but instead we do the average here across all hospitals regardless of ownership.
} 
understate the true price increases, at least for pneumonia-related events, by as much as one percentage point annually. Conversely, post-1996 price indexes that do not account for the decline in upcoding will overstate the "true" medical care price index.

We also compare the other DRG classifications by ownership type of the hospital. For stroke and TIA-related discharges, there is little or no change in not-for-profit or government ratios (a growth of 1 and 2 percentage points, respectively), and a somewhat larger increase in upcoding among for-profits of 8 percentage points between 1989 and 1996, before dropping to 75 percent in 1997 (Table 2B). Between 1989 and 1996, the percentage of total discharges coded as sepsis increased by 72 percent ( 0.8 percentage points) between 1989 and 1996 among not-for-profits, while for-profit hospitals increased by 86 percent (1.2 percentage points). In sum these two other examples of upcoding exhibit similar patterns, although the differences between for-profit and not-for-profit hospitals are not quite so pronounced as for respiratory diseases and pneumonia.

Table 3 (and Figures 2 and 3) delineates upcoding ratios according to the ownership of the hospital as well as the 1989 share of for-profit hospital discharges in the HSA. The first four columns show upcoding ratios for stable not-for-profit hospitals without any for-profit hospitals in the same town or city (Column 1), with a market share between 0 and 25 percent (Column 2), 25 to 50 percent (Column 3), and over 50 percent (Column 4). The next three columns provide upcoding ratios in for-profit hospitals (the shaded columns), while the final four columns provide ratios for government hospitals. The results suggest a generally monotonic impact of for-profit market share on the upcoding behavior of not-for-profit and government hospitals, but with little impact of for-profit market shares on upcoding behavior of for-profits. 
Focusing on for-profit hospitals for the moment, consider Figure 2, which shows upcoding ratios for two types of for-profits; one group in largely not-for-profit markets, and the other group in largely for-profit markets. There is little substantive difference in their upcoding behavior, casting doubt on the proposition that a high fraction of not-for-profit (or government) hospitals exert a moderating influence on the revenue-enhancing behavior of for-profits.

Figure 3, on the other hand, shows that the upcoding behavior of not-for-profits appears to be sensitive to the fraction of for-profit hospitals (circa 1989) operating in the market. The not-for-profit (and government) hospitals in markets with more than 50\% for-profit market share are much closer in their behavior to the for-profits in their markets.

One could argue that these patterns among not-for-profits are the consequence of forprofits being able to avoid the sickest patients. In other words, for-profits could attempt to attract healthier patients through location of clinics or new hospital facilities (Norton and Staiger, 1994), resulting in increasingly sicker patients flowing to not-for-profit and government hospitals. The sicker patients in turn would explain the higher fraction of DRG 79 coding, rather than upcoding per se. However, Appendix Table A.1 shows mortality rates broken out by hospital ownership and for-profit market share; there is no clear pattern of change in mortality rates among not-for-profits (or government hospitals) according to the market share of for-profit hospitals. It seems unlikely that changes in the true case-mix can explain the sharp variations in upcoding observed during this time period.

There are other possible explanations for this pattern. One is that not-for-profit or government hospitals in heavily for-profit markets are financially distressed because of strong competition from (revenue-enhanced) for-profit hospitals; to test this we will include as a covariate our variable measuring financial distress below. Another possibility is that Figure 3 
reflects regional effects rather than market effects. Since strong for-profit markets tend to be located in just a few states, we could attribute to market structure what is in fact simply a regional effect. Thus we also will include regional variables in our regression analysis US Census definitions of Northeast, Midwest, West, and South, plus a fifth region represented by Florida, California, Georgia, and Texas because of their heavy for-profit hospital penetration. ${ }^{15}$

For the regression analysis, our sample is of all hospitals with stable not-for-profit and government status during the period, since we want to test how for-profit market share, region, and financial distress affects the upcoding behavior of not-for-profit and government hospitals. Table 4 provides selected estimates of predicted upcoding ratios in both an OLS regression and a quantile (median) regression, weighted by total admissions for DRGs 79, 80, 89, and 90. The first and second columns provide predicted average and median upcoding ratios for the baseline not-for-profit hospital in 1989-97 normalized to the Northeast region and without any for-profit hospitals in the market. There is a steady and significant growth in upcoding ratios throughout this period; the * denotes a test (at the 5 percent significance level) of the hypothesis that the specific year upcoding ratio is different from the ratio in 1989. We also include the coefficient for government hospitals (modest differences in upcoding, as we saw earlier) and for the financial distress variable. Interestingly, the coefficients on the financial distress quintiles are the reverse of what might be expected; hospitals with the greatest apparent financial health in 1993 are those more likely to upcode.

15 For example, of the 59 not-for-profit or government hospitals that compete in HSAs with greater than $50 \%$ forprofit market share, 40 hospitals are in one of these four states. 
Columns 3 and 4 in Table 4 show predicted upcoding where we change only the share of for-profit hospitals, from zero to over $50 \%$, but hold the region constant. ${ }^{16}$ There is a substantial increase in predicted upcoding of as much as 9.8 percent in 1995 for the least-squares regression, although none of the coefficients are significant at the 0.05 level individually. However, the quantile regressions (Columns 4 versus Column 2) show effects of similar magnitude, but for these, the differences are significant during relevant years of 1994-96.

Finally, in Columns 5 and 6 of Table 4, we consider just the OLS estimated regional effects. The impact of Southern states excluding Florida, Georgia, and Texas is quite modest and not significant in the OLS regressions except in one year. However, having a not-for-profit hospital located in one of those three states or California is predictive of substantially higher (and highly significant) upcoding effects with magnitudes that are similar to those associated with increasing for-profit market share.

In sum, these regressions suggest that not-for-profit upcoding behavior is affected by the market share of for-profit hospitals and the location of the hospital. If our definitions of markets are indeed too restrictive, then some part of the regional effects may be attributable to (unmeasured) competition with or emulation of for-profit hospitals in nearby towns or cities.

A related question is the influence of the for-profit market share and region on the upcoding behavior of for-profit hospitals. Here we run a regression similar to that presented in Table 4 (albeit limited to for-profit hospitals), and find that there does not appear to be any significant influence of market share on for-profit upcoding behavior, as suggested by Figure 2 . On the other hand, there are dramatic differences in upcoding behavior of the (few) for-profits in the Northeast compared to other regions. While the predicted increase in for-profit upcoding

\footnotetext{
${ }^{16}$ There are no markets in the Northeast with more than 50 percent for-profit hospital discharges, but the results and significance would be similar if we chose another region as a baseline.
} 
between 1989 and 1996 (holding other factors constant) was 19 percent in the Midwest, 38 percent in the South, and 33 percent in the West, the prediction in the Northeast is negative and not significantly different from zero.

We next consider the behavior of hospitals that experienced a conversion from not-forprofit (or government) to for-profit status between 1989 and 1993. We consider both the upcoding ratios for those hospitals, and the upcoding ratio in the stable not-for-profits in the same HSAs. That is, the dynamic counterpart of the static comparisons above would be that notfor-profits might be more likely to increase upcoding when a hospital in their region converts from not-for-profit (or government) to for-profit.

The highest line in Figure 4 shows the upcoding ratios for the 24 hospitals that converted between 1989 and 1993. Note that the upcoding ratio peaked at 63 percent in 1996, which was higher than the entire sample of stable for-profit hospitals in the U.S. ${ }^{17}$ Clearly the converting hospitals experienced an increase in upcoding that is larger in magnitude than stable for-profits. However, Figure 4 also shows that upcoding did not change by much in the sample of stable notfor-profit and government hospitals located in the universe of HSAs that experienced a for-profit conversion. The Cutler-Horwitz hypothesis would predict that the not-for-profit and government hospitals in the same HSA would be more likely to copy the upcoding behavior of the converting hospitals. That we observe no copy-cat behavior may be the consequence of the converting hospitals simply being too small to affect the market-level norms. Among the HSAs experiencing a for-profit conversion, the median converting hospital held only a 6 percent market share. 


\section{Conclusion}

Upcoding behavior has attracted considerable attention from the federal government, but somewhat less attention from economists. While not directly related to questions regarding quality of care and pricing of care (see e.g., Lakdwawalla and Philipson, 1999, Sloan, 2000, and McClellan and Staiger, 1999), it does provide insights into the financial and risk-taking behavior of the firm. (It also avoids many of the difficult case-mix issues that bedevil comparisons between for-profits and not-for-profit institutions.) We find that, at least along the dimension of upcoding, for-profit hospitals do differ significantly from most not-for-profit (and government) hospitals with regard to upcoding behavior. The differences in upcoding cannot be explained by differences in health status or case-mix.

Our results are certainly consistent with the view that, at least on average, for-profit hospitals are more likely to engage in upcoding behavior than not-for-profit or government hospitals for a variety of reasons, including risk aversion, community trust levels, and sorting of employees. As there are a variety of models that would imply greater upcoding among forprofits, it may be more valuable to consider which models are ruled out by empirical results.

First, one might expect that large for-profit hospital chains would be the ones most likely to monitor hospital manager compliance with upcoding standards given the obvious conflict between hospital-specific profit goals and the potential costs to the chain brand-name capital (Tirole, 1996). While we did not test explicitly the hypothesis that for-profit hospital chains were less likely to upcode than individual for-profit hospitals, we find little support for this hypothesis (see for example Lagnado, 1997a and Gottlieb et al, 1997).

Second, one might anticipate that for-profit hospitals would be less likely to engage in upcoding behavior if they accounted for a small share of the hospital market; this is the (reverse)

17 However, this upcoding rate is about the same as the rate for stable for-profit hospitals in those converting HSAs. 
Hansmann (1980) hypothesis that community norms might be affected by the importance of notfor-profit hospitals in the market. However, there seems to be little evidence that for-profit hospitals are affected by the relative presence of not-for-profits. Their upcoding behavior is largely independent of whether they were operating in a heavily for-profit market or only a marginal for-profit market.

Third, not-for-profit hospital upcoding behavior is affected strongly by the share of forprofit hospitals in the market. This is not the consequence of financial distress, nor the region in which the hospital is located. This empirical pattern would appear to be consistent with the Cutler and Horwitz (2000) view that not-for-profits may emulate for-profits in the same market. On the other hand, we find less evidence that the presence of for-profit conversions elicits a response from not-for-profit hospitals in the same market, perhaps owing to bureaucratic inertia (Sloan, 2000). ${ }^{18}$

One potential model that could explain these different patterns is one that relies on differences in the objective functions (or risk tolerance) of management in the different organizational forms (Young, 1986; Arnould, Bertrand, and Hallock, 2000; Cutler and Seinfeld, 2000). Individual managers or house staff differ with regard to their tradeoff among risk, financial returns, and hospital quality. The important regional differences in upcoding are certainly consistent with this hypothesis; for-profit hospitals locate in regions where hospital administrators and physicians are more amenable to risk-taking behavior in pursuit of financial gains. Administrators and physicians who shift between for-profit and not-for-profit hospitals in the same region may engender regional "practice patterns" in upcoding, in much the same way

\footnotetext{
${ }^{18}$ Alternatively, it could be construed as support for Lakdwawalla and Philipson (1999)'s view that not-for-profits with their financial advantages operate largely independently of for-profits.
} 
that such regional patterns are observed in real health care services (Wennberg and Cooper, 1999).

Clearly, there are a variety of questions that remain to be answered. We do not address the important theoretical distinctions between government and private not-for-profit hospitals, since the government hospital is even less likely to be the residual claimant of additional upcoding fees from the Medicare program. Second, we would like to better understand the nature of hospital organizations that allowed such large increases in upcoding. In a few cases, we found nearly 100 percent upcoding ratios in hospitals, could administrators not have expected to be audited? Despite these remaining questions, we view the evidence on upcoding as suggesting that for-profit hospitals do respond to incentives in systematically different ways from not-for-profit and government hospitals.

\section{References}

Allingham, Michael G., and Agnar Sandmo, "Income Tax Evasion: A Theoretical Analysis," Journal of Public Economics 1 (1972), pp. 323-338.

Arnould, Richard Marianne Bertrand, and Kevin Hallock, "Does Market Competition Change the Nonprofit Mission? Managed Care and the Managerial Labor market in Nonprofit Hospitals," paper presented at the NBER Conference on the Industrial Organization of Medical Care, Nashville TN (April 2000).

Becker, Gary S., "Crime and Punishment: An Economic Approach,” Journal of Political Economy 76 (1968): 169-217.

Birch, Kristi, "Hospitals Report Fewer Cases of Complex Pneumonia," www.hcia.com/findings/000420_complexpneumonia.thm\#DRG (April 24, 2000).

Cutler, David M. and Jill R. Horwitz, "Converting Hospitals from Not-For-Profit to For-Profit Status: Why and What Effects?" in D. Cutler (ed.) The Changing Hospital Industry: Comparing Not-For-Profit and For-Profit Institutions Chicago: University of Chicago Press and NBER (1999). 
Cutler, David M., and Janice Seinfeld, "Managerial Background and Decision Making: Evidence from the Hospital Industry," paper presented at the NBER Conference on the Industrial Organization of Medical Care, Nashville TN (April 2000).

Duggan, Mark, "Hospital Market Structure and Medical Care for the Poor," paper presented at the NBER Conference on the Industrial Organization of Medical Care, Nashville TN (April 2000).

Frank, Richard G., and David S. Salkever, "Market Forces, Diversification of Activity, and the Mission of Not-For-Profit Hospitals," in D. Cutler (ed.) The Changing Hospital Industry:

Comparing Not-For-Profit and For-Profit Institutions Chicago: University of Chicago Press and NBER (1999).

Glaeser, Edward, and Andrei Shleifer, "Nonprofit Entrepreneurs," NBER Working Paper No. 6810 (1998).

Gottlieb, M., K. Eichenwald, and J. Barbanel, "Health Care's Giant: Powerhouse Under Scrutiny - A Special Report," New York Times (March 28, 1997), Section A, p. 1.

Hansmann, Henry B., “The Role of Nonprofit Enterprise,” Yale Law Review 89 (1980), pp. 835901.

Hsia, David C., Cathaleen A. Ahern, Brian P. Ritchie, Linda M. Moscoe, and W. Mark Krushat, "Medicare Reimbursement Accuracy Under the Prospective Payment System, 1985 to 1988," Journal of the American Medical Association 268 (7) (August 19, 1992): 896-899.

Klein, Benjamin, and Keith Leffler, "The Role of Market Forces in Assuring Contractural Performance," Journal of Political Economy (1981): 615-641.

Lagnado, Lucette, "Columbia/HCA Graded Its Hospitals on Severity of Their Medicare Claims," The Wall Street Journal (May 30, 1997a), p. A6.

Lagnado, Lucette, "Ex-Manager Describes The Profit-Driven Life Inside Columbia/HCA," The Wall Street Journal (May 30, 1997b), p. A1, A6.

Lakdwawalla, Darius and Tomas Philipson, "The Nonprofit Sector and Industry Performance," mimeo, University of Chicago (1999).

Langley, Monica, "Nonprofit Hospitals Sometimes are That in Little but Name," The Wall Street Journal (July 14, 1997): A1, A6.

McClellan, Mark, and Douglas Staiger, "Comparing Hospital Quality at For-Profit and Not-forProfit Hospitals," in D. Cutler (ed.) The Changing Hospital Industry: Comparing Not-For-Profit and For-Profit Institutions Chicago: University of Chicago Press and NBER (1999). 
Moffitt, Robert, “An Economic Model of Welfare Stigma," American Economic Review 73 (1983), pp. 1023-1035.

Newhouse, Joseph, “Towards a Theory of Non-Profit Institutions: An Economic Model of a Hospital," American Economic Review 60 (1970), pp. 64-74.

Pauly, Mark V., and Michael Redisch, "The Non-Profit Hospital as a Physician's Cooperative," American Economic Review 63 (1973), 87-100.

Polinsky, A. Mitchell, and Steven Shavell, "The Economic Theory of Public Enforcement of Law," Journal of Economic Literature 38 (March 2000): 45-76.

Psaty, Bruce M., Robin Boineau, Lewis H. Kuller, and Russell V. Luepker, "The Potential Costs of Upcoding for Heart Failure in the United States," The American Journal of Cardiology 84 (July 1, 1999): 108-109.

Sear, A.M., "Comparison of Efficiency and Profitability of Investor-Owned Multihospital Systems with Not-For-Profit Hospitals," Health Care Management Review 16(2) (1991): 31-37.

Silverman, Elaine M., Jonathan Skinner, and Elliott Fisher, "The Association Between For-Profit Hospital Ownership and Increased Medicare Spending," New England Journal of Medicine 341 (August 5, 1999), pp. 420-426.

Simborg, Donald W., "DRG Creep: A New Hospital-Acquired Disease," New England Journal of Medicine 304(26) (June 25, 1981): 1602-1604.

Skinner, Jonathan, and Joel Slemrod, “An Economic Perspective on Tax Evasion," National Tax Journal (September 1985), pp. 345-353.

Sloan, FA, Picone GA, Taylor DH, and Chou SY, "Hospital Ownership and Cost and Quality of Care: Is There a Dime's Worth of Difference?" NBER Working Paper No. 6706 (August 1998).

Sloan, Frank A., "Not-For-Profit Ownership and Hospital Behavior," in A.J. Culyer and J.P. Newhouse (eds.) Handbook of Health Economics Vol. 1B. New York: North-Holland Elsevier (2000).

Taylor DH Jr., Whellan DJ., Sloan FA., "Effects of admission to a teaching hospital on the cost and quality of care for Medicare beneficiaries," New England Journal of Medicine (January 28, 1999): 293-9.

Tirole, Jean, "A Theory of Collective Reputations (With Applications to the Persistence of Corruption and to Firm Quality)," The Review of Economic Studies 63(1) (January 1996): 1-22.

Wennberg, John E., and Megan Cooper, The Dartmouth Atlas of Health Care. Hanover NH: Dartmouth College and the American Hospital Association (1999). 
Woolhandler S., and Himmelstein DU, "When money is the mission--the high costs of investorowned care," [editorial] New England Journal of Medicine 341 (August 5, 1999), pp. 444-446.

Yitzhaki, Shlomo, “A Note on 'Income Tax Evasion: A Theoretical Analysis,"” Journal of Public Economics 3 (1974): pp. 201-202.

Young, Dennis R., "Entrepreneurship and the Behavior of Nonprofit Organizations: Elements of a Theory," in Susan Rose-Ackerman (ed.) The Economics of Nonprofit Institutions: Studies in Structure and Policy. New York: Oxford University Press (1986). 


\section{Table 1: Share of Respiratory Infection Plus Pneumonia DRGs to Total Discharges and Associated Mortality Rates, by Hospital Ownership, 1989-97}

\begin{tabular}{|c|r|r|r|r|r|r|}
\hline & \multicolumn{3}{|c|}{$\begin{array}{c}\text { Share of DRGs 79, 80, 89, and 90 to } \\
\text { Total Discharge DRGs }\end{array}$} & \multicolumn{2}{|c|}{$\begin{array}{c}\text { One-Month Mortality for All People } \\
\text { with DRGs 79, 80, 89, and 90 }\end{array}$} \\
\hline & $\begin{array}{c}\text { Not-For- } \\
\text { Profit } \\
\text { Hospitals }\end{array}$ & $\begin{array}{c}\text { For-Profit } \\
\text { Hospitals }\end{array}$ & $\begin{array}{c}\text { Gov't } \\
\text { Hospitals }\end{array}$ & $\begin{array}{c}\text { Not-For- } \\
\text { Profit } \\
\text { Hospitals }\end{array}$ & $\begin{array}{c}\text { For-Profit } \\
\text { Hospitals }\end{array}$ & $\begin{array}{c}\text { Gov't } \\
\text { Hospitals }\end{array}$ \\
\hline 1989 & .051 & .061 & .072 & .173 & .168 & .172 \\
\hline 1990 & .053 & .064 & .074 & .160 & .159 & .161 \\
\hline 1991 & .053 & .066 & .075 & .160 & .164 & .159 \\
\hline 1992 & .053 & .065 & .074 & .156 & .161 & .160 \\
\hline 1993 & .058 & .070 & .081 & .157 & .160 & .161 \\
\hline 1994 & .059 & .072 & .083 & .156 & .164 & .159 \\
\hline 1995 & .061 & .074 & .082 & .157 & .164 & .159 \\
\hline 1996 & .062 & .074 & .081 & .158 & .165 & .160 \\
\hline 1997 & .062 & .076 & .085 & .160 & .165 & .156 \\
\hline $\begin{array}{l}\text { Note: All hospitals exhibit stable ownership patterns (for-profit, not-for-profit, and } \\
\text { government) in 1989, } 1993 \text {, and 1996. }\end{array}$ \\
\hline
\end{tabular}


Table 2A: Upcoding Fraction* for Respiratory-Related Discharges, by Year and Hospital Ownership Status, 1989-97.

\begin{tabular}{|l|c|c|c|}
\hline \multicolumn{1}{|c}{ Year } & Not-for-profit & $\begin{array}{c}\text { Hospital Ownership } \\
\text { For-profit }\end{array}$ & Government \\
\hline $\mathbf{1 9 8 9}$ & 0.203 & 0.282 & 0.208 \\
\hline $\mathbf{1 9 9 0}$ & 0.207 & 0.306 & 0.209 \\
\hline $\mathbf{1 9 9 1}$ & 0.229 & 0.364 & 0.233 \\
\hline $\mathbf{1 9 9 2}$ & 0.244 & 0.423 & 0.251 \\
\hline $\mathbf{1 9 9 3}$ & 0.255 & 0.424 & 0.258 \\
\hline $\mathbf{1 9 9 4}$ & 0.266 & 0.460 & 0.274 \\
\hline $\mathbf{1 9 9 5}$ & 0.286 & 0.509 & 0.294 \\
\hline $\mathbf{1 9 9 6}$ & 0.301 & 0.516 & 0.312 \\
\hline $\mathbf{1 9 9 7}$ & 0.297 & 0.441 & 0.296 \\
\hline
\end{tabular}

*Upcoding fraction is calculated as DRG 79/( DRG 79 +DRG 80 + DRG 89 + DRG 90). Stable ownership status throughout period of analysis.

Table 2B: Upcoding Fraction* for Stroke and TIA-Related Discharges, by Year and Hospital Ownership Status, 1989-97.

\begin{tabular}{|l|c|c|c|}
\hline & \multicolumn{3}{|c|}{ Hospital Ownership } \\
\hline \multicolumn{1}{|c|}{ Year } & Not-for-profit & For-profit & Government \\
\hline 1989 & 0.71 & 0.69 & 0.71 \\
\hline 1990 & 0.71 & 0.71 & 0.73 \\
\hline 1991 & 0.72 & 0.72 & 0.73 \\
\hline 1992 & 0.72 & 0.76 & 0.74 \\
\hline 1993 & 0.72 & 0.76 & 0.73 \\
\hline 1994 & 0.71 & 0.75 & 0.72 \\
\hline 1995 & 0.72 & 0.76 & 0.74 \\
\hline 1996 & 0.72 & 0.77 & 0.73 \\
\hline 1997 & 0.72 & 0.75 & 0.73 \\
\hline
\end{tabular}

*Upcoding fraction is calculated as DRG 14 / (DRG 14 + DRG 15) 
Table 2C: Upcoding Fraction* for Sepsis, by Year and Hospital Ownership Status, 1989-97.

\begin{tabular}{|l|c|c|c|}
\hline & \multicolumn{3}{|c|}{ Hospital Ownership } \\
\hline \multicolumn{1}{|c|}{ Year } & Not-for-profit & For-profit & Government \\
\hline 1989 & & & 0.012 \\
\hline 1990 & 0.011 & 0.014 & 0.013 \\
\hline 1991 & 0.012 & 0.015 & 0.014 \\
\hline 1992 & 0.013 & 0.016 & 0.015 \\
\hline 1993 & 0.014 & 0.017 & 0.016 \\
\hline 1994 & 0.015 & 0.019 & 0.017 \\
\hline 1995 & 0.016 & 0.020 & 0.018 \\
\hline 1996 & 0.017 & 0.023 & 0.019 \\
\hline 1997 & 0.019 & 0.026 & 0.020 \\
\hline
\end{tabular}

*Upcoding fraction is calculated as DRG 416/ all discharges 
Table 3: Upcoding Ratio*, by Ownership Status and Market Structure, 1989-97

\begin{tabular}{|c|c|c|c|c|c|c|c|c|c|c|c|}
\hline & \multicolumn{4}{|c|}{ Private Not-for-Profit } & \multicolumn{3}{|c|}{ For-Profit } & \multicolumn{4}{|c|}{ Government } \\
\hline $\begin{array}{l}\text { Market } \\
\text { Share }\end{array}$ & $\begin{array}{c}\mathrm{FP}= \\
0 \%\end{array}$ & $\begin{array}{l}0 \%< \\
\mathrm{FP} \\
<=25 \%\end{array}$ & $\begin{array}{c}25 \%< \\
\mathrm{FP} \\
<50 \%\end{array}$ & $\begin{array}{c}\mathrm{FP} \\
> \\
50 \%\end{array}$ & $\begin{array}{l}0 \%< \\
\mathrm{FP} \\
<=25 \%\end{array}$ & $\begin{array}{c}25 \%< \\
\text { FP } \\
<50 \%\end{array}$ & $\begin{array}{c}\text { FP } \\
>50 \%\end{array}$ & $\begin{array}{c}\mathrm{FP}= \\
0 \%\end{array}$ & $\begin{array}{l}0 \%< \\
\mathrm{FP} \\
<=25 \%\end{array}$ & $\begin{array}{c}25 \%< \\
\text { FP } \\
<50 \%\end{array}$ & $\begin{array}{c}\text { FP } \\
>50 \%\end{array}$ \\
\hline 1989 & .195 & .215 & .236 & .200 & .295 & .270 & .280 & .198 & .216 & .244 & .264 \\
\hline 1990 & .198 & .222 & .245 & .229 & .302 & .291 & .324 & .201 & .216 & .219 & .285 \\
\hline 1991 & .219 & .242 & .276 & .288 & .356 & .350 & .388 & .217 & .261 & .230 & .318 \\
\hline 1992 & .232 & .259 & .311 & .331 & .406 & .412 & .452 & .231 & .284 & .269 & .297 \\
\hline 1993 & .242 & .270 & .335 & .330 & .397 & .433 & .445 & .243 & .280 & .251 & .362 \\
\hline 1994 & .252 & .281 & .343 & .375 & .447 & .477 & .457 & .253 & .313 & .269 & .361 \\
\hline 1995 & .270 & .306 & .363 & .433 & .491 & .550 & .487 & .270 & .320 & .323 & .431 \\
\hline 1996 & .282 & .333 & .378 & .372 & .501 & .551 & .497 & .294 & .337 & .317 & .425 \\
\hline 1997 & .286 & .313 & .341 & .352 & .441 & .456 & .426 & .275 & .333 & .300 & .345 \\
\hline
\end{tabular}

*Upcoding fraction is calculated as DRG 79/( DRG 79 +DRG 80 + DRG 89 + DRG 90). 
Table 4: OLS and Quantile Regression Models of Upcoding Among Not-for-Profit and Government Hospitals, 1989-1997

\begin{tabular}{|c|c|c|c|c|c|c|}
\hline & \multicolumn{2}{|c|}{$\begin{array}{c}\text { Base case: NFP in Northeast, } \\
\text { 0\% FP Market Share }\end{array}$} & \multicolumn{2}{|c|}{$\begin{array}{c}\text { NFP in Northeast with }>50 \% \\
\text { FP Market Share }\end{array}$} & \multirow{2}{*}{$\begin{array}{c}\text { NFP in } \\
\text { South \& with } 0 \\
\text { \% FP Market } \\
\text { Share } \\
\text { OLS }\end{array}$} & \multirow{2}{*}{\begin{tabular}{|c|} 
NFP in TX, FL, \\
GA, or CA with \\
$0 \%$ \\
FP Market \\
Share \\
OLS \\
\end{tabular}} \\
\hline & OLS & Quantile & OLS & Quantile & & \\
\hline Value in 1989 & 17.1 & 15.6 & 17.7 & 14.7 & $19.7^{\ddagger}$ & $20.6^{\ddagger}$ \\
\hline 1990 & 17.2 & 15.4 & 19.4 & $\mathbf{1 7 . 0}$ & 20.6 & 22.2 \\
\hline 1991 & $20.1 *$ & $18.6 *$ & 24.4 & $24.2^{t}$ & 21.9 & 24.7 \\
\hline 1992 & 20.4* & 19.2* & 23.7 & 22.8 & 23.2 & 26.9 \\
\hline 1993 & $21.1 *$ & $19.0 *$ & 25.1 & 21.5 & 24.9 & $29.6^{\ddagger}$ \\
\hline 1994 & $22.4 *$ & $19.7 *$ & 27.9 & $25.0^{\ddagger}$ & 27.0 & $30.2^{t}$ \\
\hline 1995 & $23.5 *$ & 21.0* & 33.3 & $29.9^{*}$ & 28.0 & 31.9 \\
\hline 1996 & $24.8 *$ & $22.2 *$ & 30.6 & $29.0^{+}$ & 30.8 & $32.4^{t}$ \\
\hline 1997 & 25.9* & $24.7 *$ & 28.1 & 28.4 & 31.2 & 31.2 \\
\hline Gov't hospital & $-0.6^{\dagger}$ & $-1.1^{\dagger}$ & & & & \\
\hline Distress (Q2) & -0.6 & $-0.9^{\dagger}$ & & & & \\
\hline Distress (Q3) & 0.4 & -0.2 & & & & \\
\hline Distress (Q4) & $2.1^{\dagger}$ & $1.3^{\dagger}$ & & & & \\
\hline Distress (Q5) & $3.5^{\dagger}$ & $2.8^{\dagger}$ & & & & \\
\hline
\end{tabular}

*Excludes Texas, Florida, and Georgia. Robust standard errors, ${ }^{\dagger}$ denotes significance at the 5 percent level, * is the 5 percent significance test of whether that year differs from 1989. ${ }^{\ddagger}$ denotes the test of whether the level of upcoding in that region differs from upcoding in the benchmark Northeast region in each year. Included in the regression, but not reported, are variables for regional midwest and west (excluding CA) dummy variables interacted with year, and coefficients for for-profit market share between 0 and 50 percent interacted with year. 
Appendix A.1: Mortality Ratio, by Ownership Status and Market Structure, 1989-97

\begin{tabular}{|c|c|c|c|c|c|c|c|c|c|c|c|}
\hline & \multicolumn{4}{|c|}{ Private Not-for-Profit } & \multicolumn{3}{|c|}{ For-Profit } & \multicolumn{4}{|c|}{ Government } \\
\hline $\begin{array}{l}\text { Market } \\
\text { Share }\end{array}$ & $\begin{array}{c}\mathrm{FP}= \\
0 \%\end{array}$ & $\begin{array}{l}0 \%< \\
\mathrm{FP} \\
<=25 \%\end{array}$ & $\begin{array}{c}25 \%< \\
\mathrm{FP} \\
<50 \%\end{array}$ & $\begin{array}{c}\mathrm{FP} \\
> \\
50 \%\end{array}$ & $\begin{array}{l}0 \%< \\
\mathrm{FP} \\
<=25 \%\end{array}$ & $\begin{array}{c}25 \%< \\
\text { FP } \\
<50 \%\end{array}$ & $\begin{array}{c}\mathrm{FP} \\
>50 \%\end{array}$ & $\begin{array}{c}\mathrm{FP}= \\
0 \%\end{array}$ & $\begin{array}{l}0 \%< \\
\mathrm{FP} \\
<=25 \%\end{array}$ & $\begin{array}{c}25 \%< \\
\mathrm{FP} \\
<50 \%\end{array}$ & $\begin{array}{c}\mathrm{FP} \\
>50 \%\end{array}$ \\
\hline 1989 & .176 & .165 & .175 & .179 & .163 & .165 & .177 & .172 & .172 & .174 & .165 \\
\hline 1990 & .161 & .156 & .164 & .168 & .158 & .156 & .162 & .158 & .170 & .156 & .159 \\
\hline 1991 & .160 & .161 & .157 & .172 & .164 & .161 & .168 & .153 & .170 & .160 & .187 \\
\hline 1992 & .152 & .161 & .173 & .155 & .163 & .149 & .171 & .159 & .165 & .157 & .139 \\
\hline 1993 & .155 & .160 & .165 & .175 & .155 & .161 & .160 & .158 & .166 & .160 & .172 \\
\hline 1994 & .156 & .154 & .155 & .180 & .168 & .160 & .163 & .157 & .169 & .142 & .155 \\
\hline 1995 & .156 & .158 & .159 & .187 & .165 & .172 & .156 & .155 & .165 & .172 & .149 \\
\hline 1996 & .156 & .162 & .170 & .139 & .169 & .165 & .160 & .157 & .167 & .162 & .132 \\
\hline 1997 & .161 & .157 & .160 & .173 & .160 & .164 & .170 & .155 & .158 & .157 & .150 \\
\hline
\end{tabular}


Figure 1: DRG 79 Relative to Other Pulmonary-Related DRGs, by Ownership Status of Hospital, 1989-97

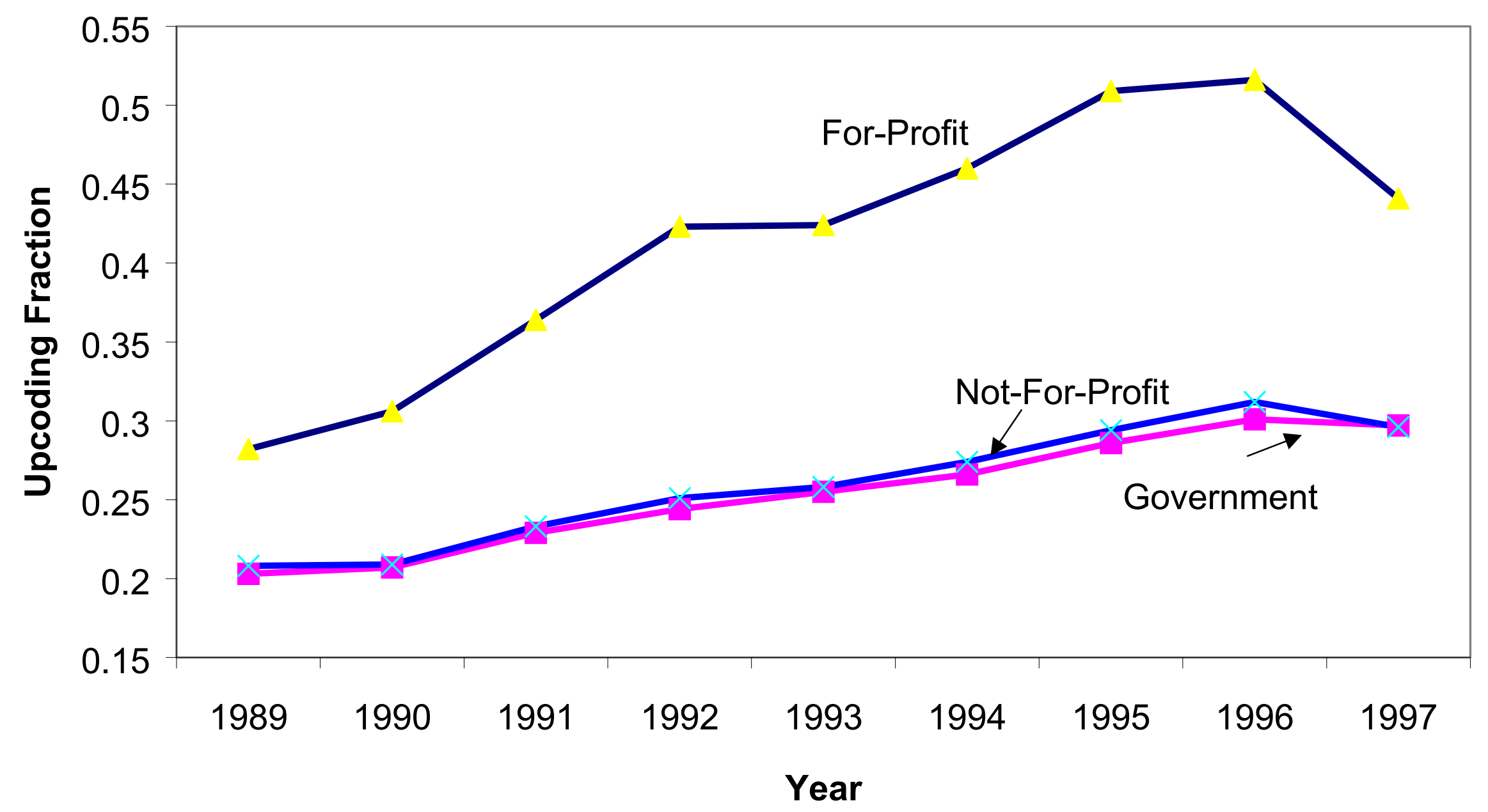


Figure 2: DRG 79 Relative to Other Pulmonary-Related DRGs, By ForProfit Ownership

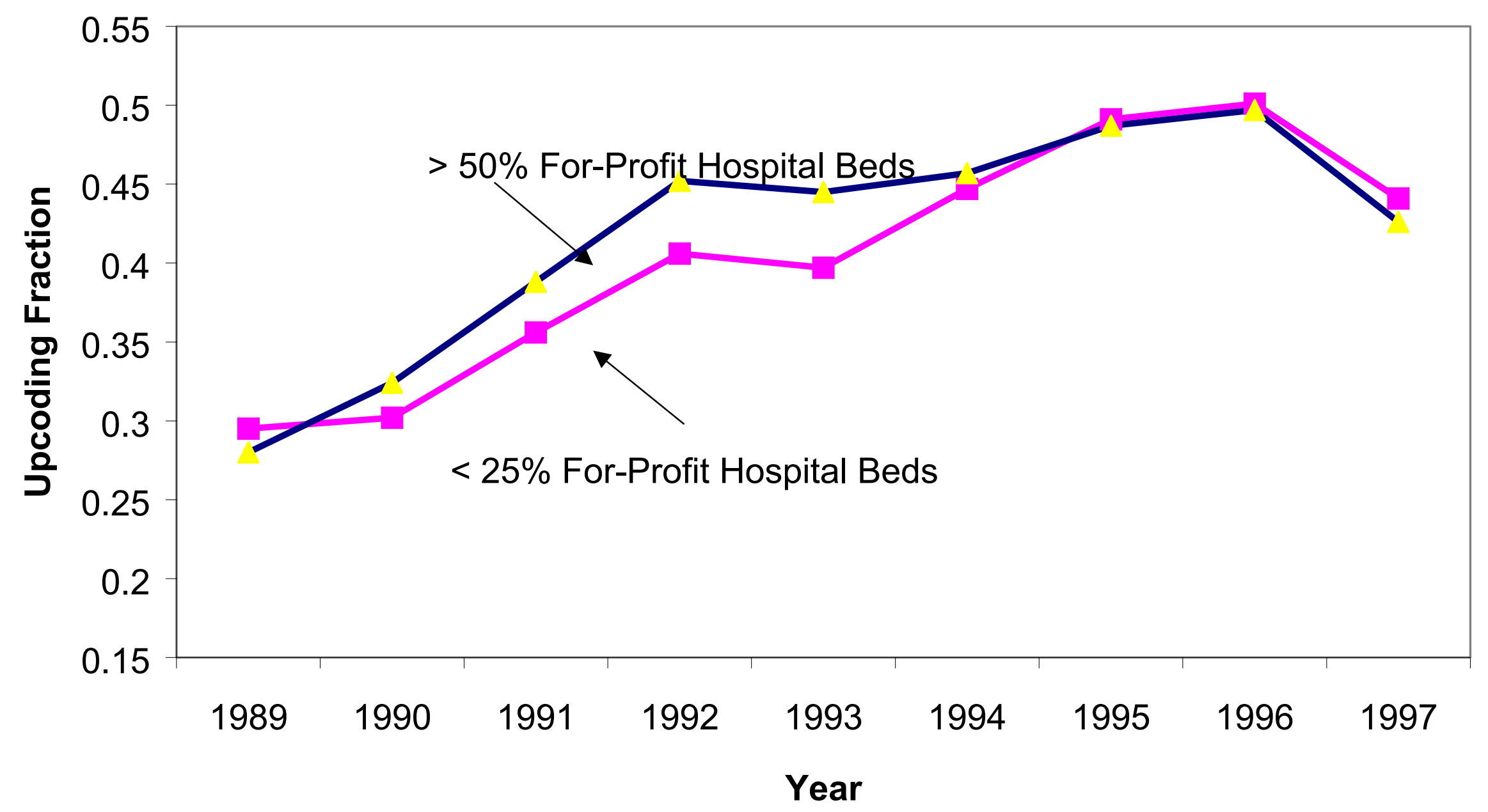


Figure 3: DRG 79 Relative to Other Pneumonia-Related DRGs, 1989-

97: Not-For-Profit Ownership

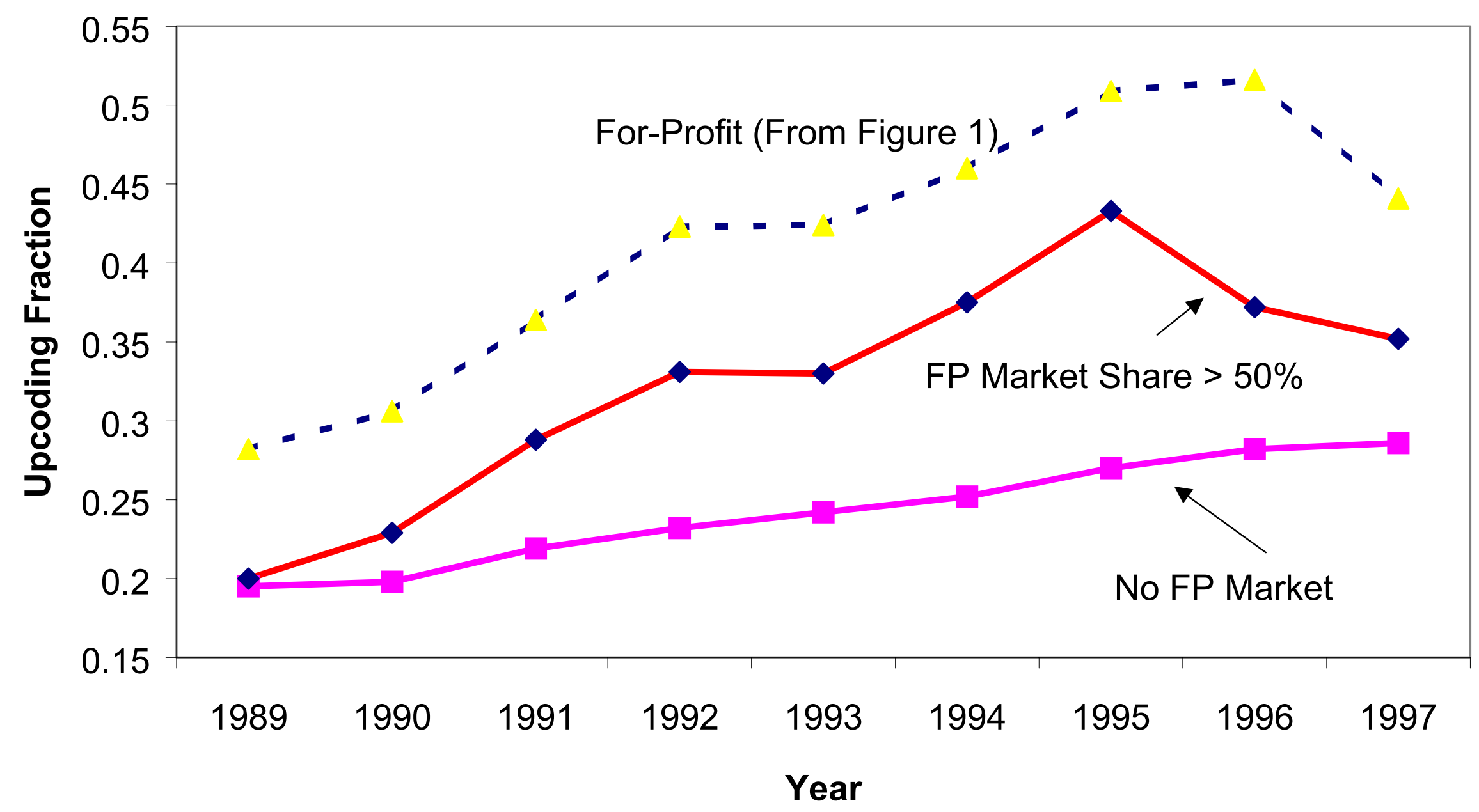


Figure 4: DRG 79 Relative to Other Pulmonary-Related DRGs,

by Conversion Status of Hospitals and HSAs, 1989-97

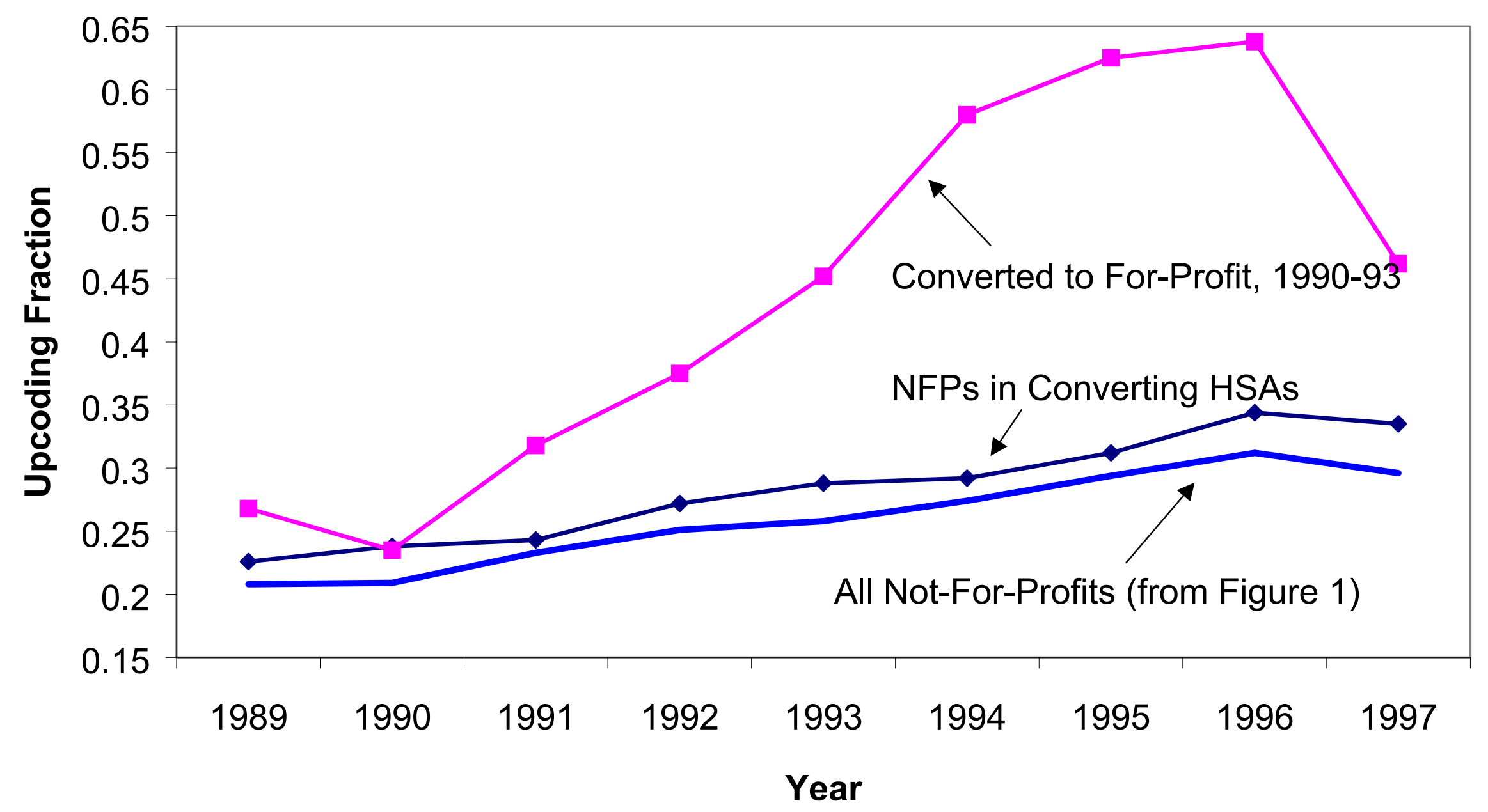

